\title{
Survival of massive allografts in segmental oncological bone defect reconstructions
}

\author{
P. H. J. Bullens • N. M. Minderhoud • \\ M. C. de Waal Malefijt • R. P. H. Veth • P. Buma • \\ H. W. B. Schreuder
}

Received: 23 September 2008 /Revised: 27 October 2008 / Accepted: 28 October 2008 / Published online: 3 December 2008

(C) The Author(s) 2008. This article is published with open access at Springerlink.com

\begin{abstract}
Reconstructions of large segmental bone defects after resection of bone tumours with massive structural allografts have a high number of reported complications including fracture, infection and non-union. Our goal is to report the survival and complications of massive allografts in our patients. A total of 32 patients were evaluated for fracture, infection, non-union rate and survival of their massive allograft reconstructions. The average follow-up for this group was five years and three months. The total fracture rate was $13 \%$ with a total infection rate of $16 \%$. We found a low union rate of $25 \%$. The total survival of the allografts was $80.8 \%( \pm 18.7 \%)$ after five years. We found a five-year allograft survival of $80.8 \%$ which is comparable with other studies.
\end{abstract}

Résumé La reconstruction des larges pertes de substances osseuses après la résection des tumeurs osseuses par des allogreffes structurales est pourvoyeuse d'un pourcentage élevé de complications, telles que fractures, infections et pseudarthroses. Le but de notre étude est de rapporter la courbe de survie et les complications de ces allogreffes massives. 32 patients ont été évalués en terme de fractures, d'infections et de pseudarthroses, après mise en place d'allogreffes massives, le suivi moyen du groupe a été de 5 ans et 3 mois. le taux de fractures est de 13\%, le taux

\section{P. Buma}

Orthopaedic Research Laboratory,

Radboud University Nijmegen Medical Centre,

P. O. Box 9101, 6500 HB Nijmegen, The Netherlands

P. H. J. Bullens • N. M. Minderhoud - M. C. de Waal Malefijt •

R. P. H. Veth $\cdot$ H. W. B. Schreuder $(\bowtie)$

Department of Orthopaedic Surgery,

Radboud University Nijmegen Medical Centre,

P. O. Box 9101, 6500 HB Nijmegen, The Netherlands

e-mail: h.schreuder@orthop.umcn.nl d'infections de $16 \%$. Nous avons trouvé un taux relativement bas de consolidation $25 \%$. La survie de ces allogreffes, globalement est de $80,8 \%( \pm 18,7 \%)$ après 5 ans. le taux de survie de ces allogreffes à plus de 5 ans est de $80,8 \%$, il est comparable aux autres études.

\section{Introduction}

Limb-saving surgery of bone tumours has increased due to improvement in imaging, adjuvant chemotherapy and radiotherapy. Bone tumour resections result in large segmental bone defects. Large massive cortical allografts, large endoprostheses or a combination of both (composite) are the state of the art for reconstruction. Allograft fixation can be achieved with internal fixation devices (plate, intramedullary nail) as an intercalary graft or with the stem of an endoprosthesis (composite) [3, 4, 8]. However, the use of massive allografts has a high number of reported complications such as like fracture, infection and non-union [2-4]. The purpose of this study was to analyse the number of complications (fracture, infection, non-union) and survival of massive allograft reconstructions in our patients.

\section{Patients and methods}

Our investigation encompasses 32 patients who had a cylindrical segmental allograft reconstruction of the femur, tibia or humerus. All 32 reconstructions were performed between April 1992 and May 2005 at our department. The mean age of the 18 female and 14 male patients was 27 years (range: 6-78 years) at the time of operation.

The diagnoses included 14 osteosarcomas, five Ewing's sarcomas, five chondrosarcomas, two adamantinomas, three 
giant cell tumours, one plasmacytoma, one haemangioma and one haemangioendothelioma. The minimum follow-up was one year, except in cases of death or allograft failure. The average follow-up was five years and three months (range: 1 month-14 years and 4 months). No patients were lost to follow-up.

In 18 cases the lesion was close to the joint and the defect was reconstructed with an allograft-prosthesis (Waldemar Link, Hamburg, Germany) composite and included eight knee, six hip and four shoulder prostheses. In these patients the graft was fixed by means of the stem of the endoprosthesis (Fig. 1). An allograft in combination with an arthrodesis nail (Waldemar Link, Hamburg, Germany) was used in three patients after resection of the knee joint including the extensor apparatus. In 11 cases with adequate margins in relation to the joints, fixation of an intercalary allograft was performed with an intramedullary nail and/or plate (Synthes, Philadelphia, PA, USA).

Of the total group 15 defects were reconstructed in the femur, 11 in the tibia and six in the humerus, with a total of 43 host-donor junctions. Of these, 11 were metaphyseal and 32 were diaphyseal junctions.

The surgical procedure consisted of resection of the lesion with appropriate bone and soft tissue margins. All grafts were fresh deep-frozen. The allograft was thawed in a warm saline solution, cut to proper length, sized to fit the bone defect and inserted. All allograft-host junctions were made with a transverse osteotomy. Antibiotics (Cefacidal 3 times $1 \mathrm{~g}$ ) were given intravenously according to a standard prophylactic protocol.

Progressive passive range of motion exercises started one week after surgery, followed by partial weight-bearing until 12 weeks postoperatively. After three months full

Fig. 1 Fixation of the allograft with the stem of the endoprosthesis, non-union 24 months postoperatively weight-bearing was allowed. Most patients were seen postoperatively at three months, six months, one year, two years, five years and then every three years. Plain radiographs were taken at every visit and the functional score of the Musculoskeletal Tumour Society (MTST) was recorded.

The clinical records and all the follow-up radiographs were reviewed for each patient. Union of the allograft-host junction was considered to have occured if the junction line was no longer visible or the junction was bridged by periosteal bone on the anteroposterior and lateral radiographs. The allograft survival rate was estimated using the Kaplan-Meier test. Fracture/failure of the reconstruction or allograft removal either as a revision procedure or amputation was considered as an endpoint of survival.

\section{Results}

A fracture occurred in four patients (13\%). Two patients had a reconstruction with plate fixation and two a reconstruction with an arthrodesis nail. In five patients an infection was observed (16\%). Infection occurred in two patients with internal fixation, one with an arthrodesis nail and in two patients with an endoprosthesis. Non-union was observed in four patients with internal fixation and in 12 patients with an endoprosthesis leading to a union rate of $25 \%$. Overall survival of the 32 allograft reconstructions was $93.5 \pm 8.6 \%$ at one year and $80.8 \pm 18.7 \%$ at five years (Fig. 2). The average postoperative MTST functional score of the group was 21.8 points (max. 30 ) or $72.7 \%$ at the last follow-up.

\section{Complications}

Of the 32 patients, four patients died of pulmonary metastases during follow-up. In these patients the last examination was taken as follow-up.

Twenty-five patients were continuously disease free, and three patients had no evidence of disease after resection of a local recurrence.

Three patients had an amputation. In one patient with an endoprosthesis an amputation was carried out after

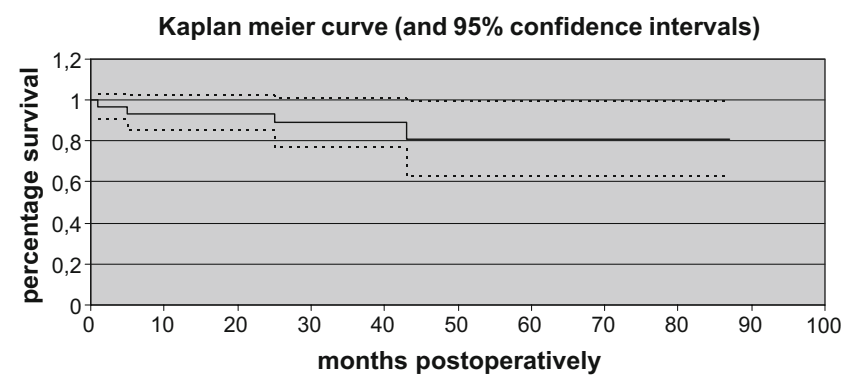

Fig. 2 Survival curve of the massive allograft reconstructions 
one month when positive margins of the resection were found. One patient had an amputation after five months due to a deep infection of the intercalary graft. The third patient had an amputation of graft and endoprosthesis after 87 months for local recurrence.

One patient had an intercalary allograft removed due to a deep infection (at 159 months). After débridement and removal of the graft a mega-prosthesis was implanted. Two patients with an endoprosthesis had a deep infection leading to a chronic fistula which was not treated. In the intercalary graft group two plate fractures were observed leading to a stable fibrous non-union in one and a revision in the other (Fig. 3). All three patients with an arthrodesis nail suffered from complications. One had a deep infection which was débrided and treated with local antibiotics and two developed a fracture of the arthrodesis nail which was treated with a revision of the nail.

\section{Discussion}

The high fracture rate of up to $38 \%$ after allograft reconstructions reported in several studies was related to irradiation, stress concentration near the end of a fixation device and screw holes used for plate fixation [10, 13, 14, 18]. The fracture risk of plate fixation is supported by our study, as two of the four fractures that occurred were after plate fixation. The fracture rate of $13 \%$ was low in our study group probably due to a high number of patients treated with an endoprosthesis with a long solid stem.

Reconstructions with an arthrodesis nail are associated with a high rate of complications and a reported survival of $54 \%$ after five years [9]. Donati et al. [5] reported reoperations after arthrodesis nail reconstructions in more than $50 \%$ in their study. Although we only used the arthrodesis nail in three patients complications occurred in

Fig. 3 Non-union and failure of fixation in an intercalary allograft reconstruction all (two fractures and one infection). Failure is most likely caused by high concentrations of stress at the site of the former knee joint and ends of the fixation. It seems that the arthrodesis nail should be used only in cases where no alternatives are available.

Our infection rate was $16 \%$. These rates are comparable with other studies that reported rates varying from 8 to $19 \%$ $[3,4,12]$.

Non-union was seen in $68 \%$ of the total group. Nonunion was related to fixation with an endoprosthesis in $75 \%$. This relatively high number of non-unions is probably caused by stress shielding of the large stems that leave the osteotomy site relatively unloaded. Despite non-union an endoprosthesis in combination with an allograft appeared to be stable since no failures of reconstruction were observed in this group. Non-union was seen in $44 \%$ of the patients with an intercalary graft with internal fixation. Non-union in combination with a plate fixation led to failure of fixation in $50 \%$. Non-union seems to be a risk factor for failure in the group with a plate fixation device. The union rate is reported to be influenced by stability of fixation and degree of contact between host and graft. Other factors decreasing union rates are chemotherapy and radiation [9, 10, 13, 14]. Metaphyseal junctions have a lower non-union rate as compared to the cortical diaphyseal junctions $[3,4,6]$. This difference will also influence the non-union rate of the endoprosthetic reconstructions in which the grafts have predominantly diaphyseal junctions.

Deijkers et al. [3, 4] reported a functional MSTS score of $77 \%$ after segmental reconstructions. Lietman et al. [10] reported a range of $58-92 \%$ MSTS score. The average functional score of $73 \%$ in our study is comparable with these reports.

The five-year survival of $81 \%$ of all the allograft reconstructions in our study is consistent with others [11, 20]. Mankin et al. [11] reported an allograft survival of $76 \%$. In this last study a subgroup with intercalary grafts had a survival of $84 \%$ compared to $73 \%$ of osteoarticular grafts and $77 \%$ for allograft-endoprosthesis reconstructions. Musculo et al. [13, 14] reported an intercalary graft survival of $79 \%$ after five years. Enneking and Campanacci [6] reported only partial incorporation of the allograft in a retrieval study and union occurred slowly with an average of 12 months. These findings indicate that the allograft only partially supports the overall strength of the entire reconstruction. Since intramedullary nails and plates are only intended as a temporary fixation, we anticipated a higher failure rate in this group as in the study of Wedin and Bauer [19] who reported a lower failure rate in endoprosthetic reconstructions of metastatic lesions in the proximal femur compared to reconstruction nails. However, we found no difference in survival between massive allograft fixation with an endoprosthesis or internal fixation device. Cement 
used to augment internal fixation could improve the strength of the reconstruction [7]. Cement, however, will be more demanding to manage in revision procedures and may obstruct a biological fixation.

A study of Zehr et al. [21] showed fewer dislocations of a composite reconstruction compared to a reconstruction with only a mega-prosthesis. An endoprosthesis in combination with an allograft has the advantage of load sharing. Furthermore, tendons can be reattached to soft tissue left on the graft. A composite reconstruction is more often complicated by infections. The survival of the composite was better than the mega-prosthesis although the difference was not significant.

Reconstructions with an endoprosthesis lead to a predictable outcome. Endoprosthetic reconstructions, however, are associated with complications such as loosening and dislocation of the implant $[15,17]$ causing the survival of an endoprosthesis to deteriorate in time.

Reconstructions with intercalary grafts are less predictable due to a higher complication rate in the first three years. After three years the survival of intercalary grafts remains stable [1]. A further advantage of intercalary grafts is the preservation of the opposite growth plate in the young $[2,16]$. Each method of fixation has its own advantages, indications and limitations.

The numbers in this study are too small to draw firm conclusions. The comparison with other studies is difficult because every reconstruction is different in diagnosis, localisation, fixation, adjuvant therapy, soft tissue envelope and size of the defect. Host-graft contact and size fitting of the graft are other important factors influencing results $[3,4,13$, 14]. The study has a limited follow-up although sufficient as failure predominantly occurs in the first three years $[3,4]$.

\section{Conclusions}

We found a five-year survival of massive allograft reconstructions of $80.8 \%$, which is comparable with other studies.

Open Access This article is distributed under the terms of the Creative Commons Attribution Noncommercial License which permits any noncommercial use, distribution, and reproduction in any medium, provided the original author(s) and source are credited.

\section{References}

1. Brien EW, Terek RM, Healey JH, Lane JM (1994) Allograft reconstruction after proximal tibia resection for bone tumors. An analysis of function and outcome comparing allograft and prosthetic reconstructions. Clin Orthop Relat Res 303:116-127

2. Brigman BE, Hornicek FJ, Gebhardt MC, Mankin HJ (2004) Allografts about the knee in young patients with high-grade sarcoma. Clin Orthop Relat Res 421:232-239

3. Deijkers RLM, Bloem RM, Kroon HM, Lent JB, Brand R, Taminiau AHM (2005) Epidiaphyseal versus other intercalary allografts for tumors of the lower limb. Clin Orthop Relat Res 439:151-160

4. Deijkers RLM, Vehmeyer SBW, Bloem RM, Obermann WR, Taminiau AHM (2005) Allograft-prosthesis composite reconstruction of the proximal femur for bone tumours. Thesis, Leiden, The Netherlands. ISBN 90-9018953-X

5. Donati D, Giacomini S, Gozzi E et al (2002) Allograft arthrodesis treatment of bone tumors: a two-center study. Clin Orthop Relat Res 400:217-224

6. Enneking WF, Campanacci DA (2001) Retrieved human allografts: a clinicopathological study. J Bone Joint Surg Am 83-A (7):971-986

7. Gerrand CH, Griffin AM, Davis AM et al (2003) Large segment allograft survival is improved with intramedullary cement. J Surg Oncol 84(4):198-208

8. Heisel C, Kinkel S, Bernd L, Ewerbeck V (2006) Megaprostheses for the treatment of malignant bone tumours of the lower limbs. Int Orthop 30(6):452-457

9. Hornicek FJ, Gebhardt MC, Tomford WW et al (2001) Factors affecting nonunion of the allograft-host junction. Clin Orthop Relat Res 382:87-98

10. Lietman SA, Tomford WW, Gebhardt MC, Springfield DS, Mankin HJ (2000) Complications of irradiated allografts in orthopaedic tumor surgery. Clin Orthop Relat Res 375:214-217

11. Mankin HG, Gebhardt MC, Jennings LC et al (1996) Long term results of allografts replacement in the management of bone tumors. Clin Orthop 324:86-97

12. Matejovsky Z Jr, Matejovsky Z, Kofranek I (2006) Massive allografts in tumour surgery. Int Orthop 30(6):478-483

13. Muscolo DL, Ayerza MA, Aponte-Tinao L, Ranalletta M, Abalo E (2004) Intercalary femur and tibia segmental allografts provide an acceptable alternative in reconstructing tumor resections. Clin Orthop Relat Res 426:97-102

14. Muscolo DL, Ayerza MA, Aponte-Tinao LA (2006) Massive allograft use in orthopedic oncology. Orthop Clin North Am 37 (1):65-74

15. Orlic D, Smerdelj M, Kolundzic R, Bergovec M (2006) Lower limb salvage surgery: modular endoprosthesis in bone tumour treatment. Int Orthop 30(6):458-464

16. Ramseier LE, Malinin TI, Temple HT, Mnaymneh WA, Exner GU (2006) Allograft reconstruction for bone sarcoma of the tibia in the growing child. J Bone Joint Surg Br 88(1):95-99

17. Unwin PS, Cannon SR, Grimer RJ et al (1996) Aseptic loosening in cemented custom-made prosthetic replacement for bone tumours of the lower limb. J Bone Joint Surg Br 78:5-13

18. Vander Griend RA (1994) The effect of internal fixation on the healing of large allografts. J Bone Joint Surg Am 76(5):657-663

19. Wedin R, Bauer HCF (2005) Surgical treatment of skeletal metastatic lesions of the proximal femur: endoprosthesis or reconstruction nail? J Bone Joint Surg Br 87(12):1653-1657

20. Zeegen EN, Aponte-Tinao LA, Hornicek FJ et al (2004) Survivorship analysis of 141 modular metallic endoprostheses at early followup. Clin Orthop Relat Res 420:239-250

21. Zehr RJ, Enneking WF, Scarborough MT (1996) Allograftprosthesis composite versus megaprosthesis in proximal femoral reconstruction. Clin Orthop Relat Res 322:207-223 